Check for updates

Cite this: RSC Adv., 2019, 9, 21134

Received 15th May 2019

Accepted 20th June 2019

DOI: $10.1039 / c 9 r a 03662 h$

rsc.li/rsc-advances

\section{Size dependent anti-invasiveness of silver nanoparticles in lung cancer cells $\dagger$}

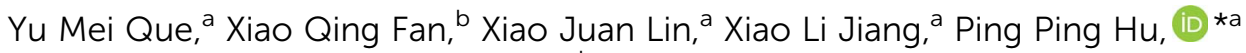 \\ Xiao Yong Tong ${ }^{a}$ and Qun You Tan*b
}

The molecular mechanism of cancer cell death caused by silver nanoparticles (AgNPs) of different sizes is investigated. Compared with the larger nanoparticles, $13 \mathrm{~nm}$ AgNPs significantly inhibit the migration and invasiveness of lung adenocarcinoma A549 cells, induce elevated reactive oxygen species and lead to $\mathrm{NF}-\kappa \mathrm{B}$ directed cellular apoptosis.
Lung cancer is the most commonly diagnosed malignancy, which is reported to account for about 1.82 million new cases and 1.59 million mortalities globally in 2012. ${ }^{1}$ Non-small cell lung cancer (NSCLC) is one deadly type of lung cancer, which occurs in approximately $85 \%$ to $90 \%$ of all cases. Various treatment options have been available in recent years, such as minimally invasive surgical treatment, radiation therapy, systemic chemotherapy and targeted therapy, however, the treatment regimens mainly rely on the disease stage or performance status, and the long-term survival of patients with NSCLC is dismal. For example, only $13-36 \%$ of patients with NSCLC survive five years after diagnosis., ${ }^{2,3}$ Moreover, lung cancer, with many variants, frequently metastasize to bone, brain, lung and liver, and drugs that target distant metastases often do not work in the adjuvant settings, ${ }^{4}$ or worse, wreak havoc on healthy cells and tissues, ${ }^{5,6}$ causing poor prognosis and high mortality. ${ }^{7,8}$ Thus, new therapies that overcome the current obstacles such as drug resistance, side effects, and poor specificity provide hope for the treatment of NSCLC in the future.

During the last two decade, with the development of nanotechnology, nanoparticles have gained growing interest as promising agents and have been applied for biomedical research $^{9-12}$ including drug manufacture, imaging, biological tagging, anticancer drugs, drug delivery, antibiotic development, gene transmission, tissue engineering, etc. Although more research is necessary, various nanoparticles play an intimate role in therapeutics and diagnostic agents, which has high specific surface area and easily penetrate the cell membranes and the biological barriers.

${ }^{a}$ Chongqing Key Laboratory of Natural Product Synthesis and Drug Research, School of Pharmaceutical Sciences, Chongqing University, Chongqing 401331, PR China. E-mail: huping07@163.com

${ }^{b}$ Department of Thoracic Surgery, Institute of Surgery Research, Daping Hospital, Army Medical University, Chongqing 400042, P. R. China. E-mail: tanqy001@163.com

$\dagger$ Electronic supplementary information (ESI) available. See DOI: 10.1039/c9ra03662h
Silver nanoparticles (AgNPs) are emerging as one of the fastest growing nanotechnology-based product categories, and they have been successfully used for both in vivo and in vitro anticancer therapies because they are easy to make and stable. ${ }^{13-15}$ It has been presented that AgNPs and their related products including surgical instruments and wound dressings show wide spectrum of biological activities and strong inhibitory effect on the growth, thus suggesting their widespread applications as nanomedicine. ${ }^{16-18}$ Nevertheless, the molecular mechanism of cancer cell death caused by treatment of AgNPs seem to be still under investigation, although much research pointed out that, at the nano-scale, size is considered as one of the important criteria that governs the physicochemical properties of nanoparticles and ultimately their biological behaviour. In the present study, the effects of AgNPs with different sizes against A549 lung adenocarcinoma (a common type of NSCLC) cells was explored, and the data demonstrated that the smaller AgNPs $(13 \mathrm{~nm})$ were more toxic and significantly suppressed the migratory and invasive abilities of A549 cells, while no such changes were observed with larger nanoparticles. Furthermore, we found that $13 \mathrm{~nm}$ AgNPs inhibited the growth and invasion of lung cancer cells in vitro by inducing apoptosis via NF- $\mathrm{B}$ signaling pathway, accompanied by the up-regulation of pro-apoptotic proteins and the down-regulation of antiapoptotic proteins. These are promising observations and provide valuable information on the size-dependent anticancer activity of AgNPs for potential human applications against invasion of lung adenocarcinoma.

Experimentally, AgNPs with different sizes were successfully synthesized. ${ }^{19-21}$ SEM images of AgNPs (Fig. 1a-c) revealed that the as-prepared AgNPs were well dispersed with uniform sizes. By counting the nanoparticles in the SEM images, the average particle sizes were calculated, which were 13.02, 45.21 and $92.18 \mathrm{~nm}$ (Fig. 1a-c, inset histograms), and termed to be 13, 45 and $92 \mathrm{~nm}$ in the following study. Moreover, as Fig. $1 \mathrm{~d}$ showed, AgNPs with the size of 13, 45 and $92 \mathrm{~nm}$ have surface plasmon absorption at 388, 408 and $468 \mathrm{~nm}$, respectively, which is 


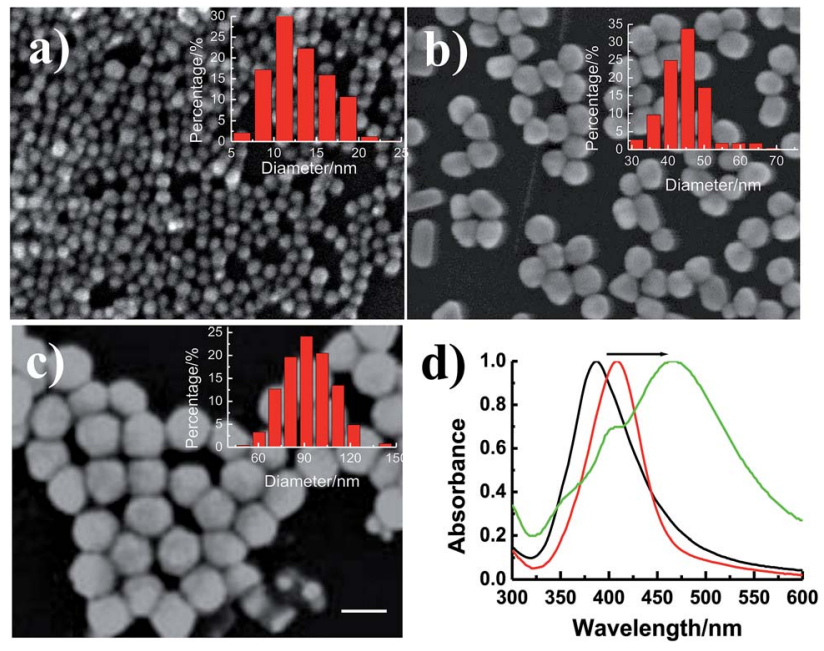

Fig. 1 SEM images and corresponding size distributions of AgNPs. The average particle sizes are $13.02 \mathrm{~nm}$ (a), $45.21 \mathrm{~nm}$ (b) and $92.18 \mathrm{~nm}$ (c). The total numbers of particles counted for the histograms are more than 100. Scale bar: $100 \mathrm{~nm}$. (d) Extinction spectra of AgNPs with the size of $13.02 \mathrm{~nm}$ (black), $45.21 \mathrm{~nm}$ (red) and $92.18 \mathrm{~nm}$ (green).

identical to that of the plasmon resonance absorbance signals of AgNPs in aqueous medium.

The primary challenges of preparing nano-materials suitable in biological-medical area are to keep the nanoparticles away from aggregation and retain constant physicochemical properties in physiological conditions. It has been observed that there was no significant change in the absorption peak of AgNPs incubated with cell medium up to $72 \mathrm{~h}$ (Data not shown). MTT assay was then performed to assess the cytotoxicity of the AgNPs. Various concentrations of AgNPs (13, 45 and $92 \mathrm{~nm})$ were incubated with A549 and L929 cells (mouse subcutaneous connective tissue and fat fibroblast cell, as the normal control) for up to $72 \mathrm{~h}$, and the cell viabilities were measured. Cell viability of L929 cells was observed to be over $80 \%$ as compared to untreated cells at all the sizes and maximum concentration, and no obvious changes were observed at different time (Fig. S1 $\dagger$ ), suggested that AgNPs in the size range of 13-92 nm and the concentration range used in this work are largely nontoxic to normal cells. The anti-proliferation effect of AgNPs against A549 cells was evaluated at the same experiment condition, which showed higher cytotoxicity in dose-, time- and size-dependent manners and smaller AgNPs increased the toxicity against A549 cells, which is consisted with previous report. ${ }^{22}$ Based on those results, the relatively low concentrations of AgNPs ( $13 \mathrm{~nm}, 1.0 \mu \mathrm{g} \mathrm{mL}^{-1} ; 45 \mathrm{~nm}, 3.0 \mu \mathrm{g} \mathrm{mL}{ }^{-1}$; $92 \mathrm{~nm}$, $20 \mu \mathrm{g} \mathrm{mL}{ }^{-1}$ ) were provided for the further experiments (cell viability > 90\% and 70\% for L929 and A549 cells, respectively).

As known, metastasis is the main characteristic of cancer, during which the metastatic cells migrate from the primary tumour to a distant tissue, invade surrounding tissues for entering blood and lymphatic circulations, and ultimately grow into a macroscopic metastatic lesion. ${ }^{23-25}$ To evaluate the size effect of AgNPs on migration of A549 cells, a wound healing assay was employed. The results demonstrated that the cells treated with AgNPs of 13 and $45 \mathrm{~nm}$ migrated more slowly to close the scratched wounds compared with that of $92 \mathrm{~nm}$ AgNPs and untreated A549 group (Fig. 2).

Furthermore, a transwell invasion assay was then performed to investigate the effect of AgNPs on the invasive abilities of A549 cells. Fig. 3 showed that the ability of A549 cells to invade through the matrigel matrix was significantly decreased incubated with $13 \mathrm{~nm}$ AgNPs, while the invasion of A549 cells was inhibited to some extent when incubated with $45 \mathrm{~nm}$ AgNPs, and no such effect was observed in $92 \mathrm{~nm}$ AgNPs treated or A549-con group (Fig. 3). Taken together, these results suggested that $13 \mathrm{~nm}$ AgNPs could significantly inhibit the migratory and invasive abilities of A549 cells in vitro, and no similar effect was observed at the size of $92 \mathrm{~nm}$.

To investigate the mechanism of the halted migratory and invasive abilities of A549 cells caused by AgNPs, subcellular localization of AgNPs was then performed under a dark-field microscope, and we could clearly observe the distribution of AgNPs in cytoplasm of A549 cells (Fig. S2 $\dagger$ ). In the control group, however, under the same condition, there was no significant number of particles except the obvious aggregated dots driving from the non-specific adsorption, indicated that AgNPs could successfully and efficiently entered the cells via endocytosis and accumulated in cytoplasm. Interestingly, more dark-field light scattering signal was obtained in the $13 \mathrm{~nm}$ AgNPs treated A549 cells due to the small size effect.

Reactive Oxygen Species (ROS) are the natural by-products of normal metabolism and play crucial roles in cell signalling and homeostasis, most of which are generated by oxidative phosphorylation (OXPHOS) in mitochondria. Increasing level of intracellular ROS induced by chemotherapeutic drugs may result in significant damage to cell morphology and lead to cell death. ${ }^{26}$ In order to determine the potential effect of AgNPs to ROS generation, dihydroethidium (DHE) staining was then involved (Fig. 4). DHE is a widely used probe, which shows very weak fluorescence and turns into significant enhanced fluorescent signal when oxidized by ROS or some other peroxides in cells. As shown in Fig. 4, AgNPs of different sizes showed distinct effect on intracellular ROS level. After exposure to $13 \mathrm{~nm}$ and $45 \mathrm{~nm}$ AgNPs, the cells showed strong red fluorescence (Fig. $4 \mathrm{~b}$ and c), and the fluorescence of DHE was strongest

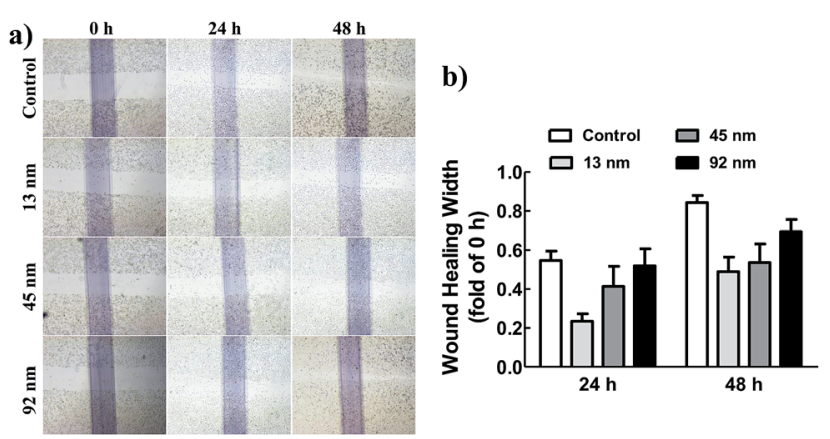

Fig. 2 AgNPs with the size of 13 and $45 \mathrm{~nm}$ inhibited A549 cell migration in vitro. (a) Representative photographs of wound healing scratch assay. (b) The bar graphs show the number of migrating cells. 
a)

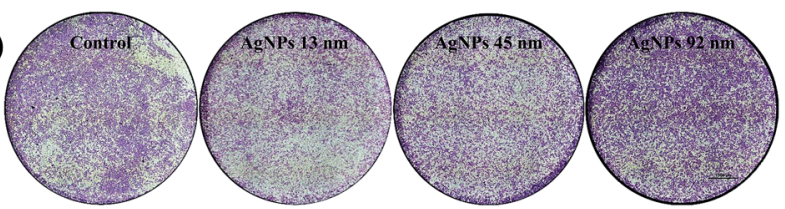

b)

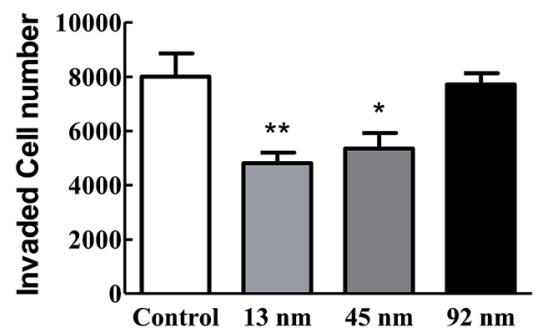

Fig. 3 Transwell migration assay. (a) Representative photographs of transwell migration assay with A549 cells with or without pre-treatment of AgNPs. Scale bar: $1000 \mu \mathrm{m}$. (b) The migration cell numbers for each group were calculated.

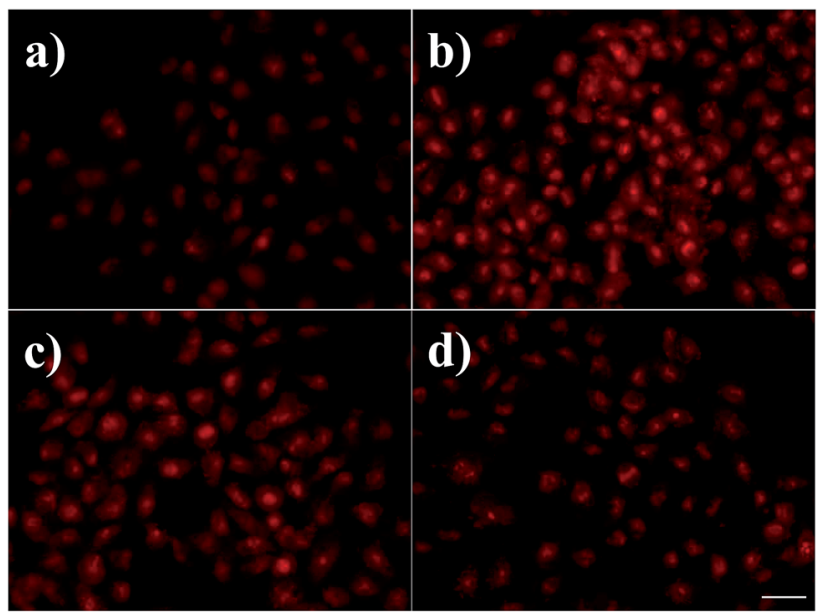

Fig. 4 ROS generation in A549 cells control (a), and cells treated with $13 \mathrm{~nm}$ (b), 45 nm (c), 92 nm AgNPs (d). Scale bar: $100 \mu \mathrm{m}$.

in cells incubated with $13 \mathrm{~nm}$ AgNPs, whereas in the untreated control cells (Fig. 4a) and that treated by $92 \mathrm{~nm}$ AgNPs (Fig. 4d) quite poor fluorescence was observed, suggesting that 13 and $45 \mathrm{~nm}$ AgNPs-treatment induced oxidative stress. As more number of red fluorescent cells have been noted during treatment of the smaller AgNPs ( 13 and $45 \mathrm{~nm}$ ), the size-dependent cytotoxicity might be caused due to elevated level of ROS in A549 cells treated by smaller AgNPs, which could penetrate cell membrane and located in the lysosome and mitochondria, ${ }^{27,28}$ and subsequently lead to cellular/DNA damages. ${ }^{29}$

To further clarify the effect of size on lung cancer cell death, cell apoptosis studies were investigated in A549 cells treated by AgNPs, and the protein levels of apoptosis related protein-Bax, Bcl-2 and Bad were determined. As shown in Fig. 5, the content of Bad, which is anti-apoptotic, increased significantly after incubated with $13 \mathrm{~nm}$ AgNPs, while no obvious changes were obtained when the cells were treated with larger a)

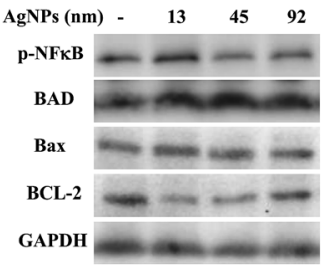

b)

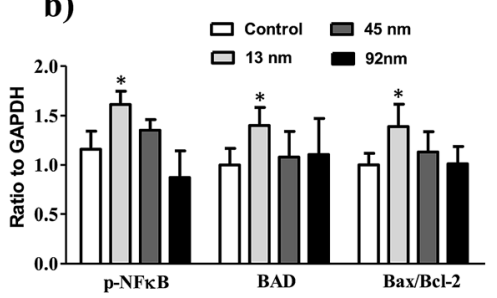

Fig. 5 Treatment with smaller size AgNPs modulates the expression of proteins related to NF- $\kappa \mathrm{B}$ directed cell apoptosis. (a) A549 cells ( $1 \times$ $10^{6}$ /plate) were seeded and incubated with AgNPs of different size for $24 \mathrm{~h}$, total protein was isolated and subjected to immunoblot analysis for cell survival related proteins namely $p-N F-\kappa B, B A D, B c l-2$ and $B a x$ followed by densitometry of immunoreactive bands. GAPDH was used as a loading control. (b) Bar diagram represents the $\mathrm{p}-\mathrm{NF} \kappa \mathrm{B} / \mathrm{GAPDH}$, $\mathrm{BAD} / \mathrm{GAPDH}$ and $\mathrm{Bax} / \mathrm{Bcl}-2$ ratio in different treatment group. Lines within the groups represent averages \pm standard errors. ${ }^{*} p<0.05$.

nanoparticles. Similarly, $13 \mathrm{~nm}$ AgNPs causes a reduction in the levels of the anti-apoptotic protein Bcl-2, while an associated increase in the level of pro-apoptotic protein Bax was observed (Fig. 5), leading to an increase in the ratio of Bax/Bcl-2.

Much experimental research has reported that the inhibition of nuclear factor (NF)- $\mathrm{KB}$ activation can lead to the inhibition of cell growth, invasion and apoptosis in various types of cancer cells. ${ }^{31-33}$ Following this line, the activity of NF-kB in A549 cells was further analysed to investigate the possible apoptotic mechanism, and the results revealed that $13 \mathrm{~nm}$ AgNPs was able to significantly upregulate the phosphorylation of NF- $\mathrm{KB}$ (p-NF$\kappa B)$ in A549 cells (Fig. 5). These results suggest a potential apoptotic effect of $13 \mathrm{~nm}$ AgNPs against A549 cells via the NF- $\mathrm{KB}$ signalling pathway. Based on all of the above results, we speculate that, AgNPs, which are pointed out that have a sustained release of $\mathrm{Ag}^{+}$in an environment with lower $\mathrm{pH}$ (such as cancer cells), ${ }^{30}$ may create free radicals and induce oxidative stress,

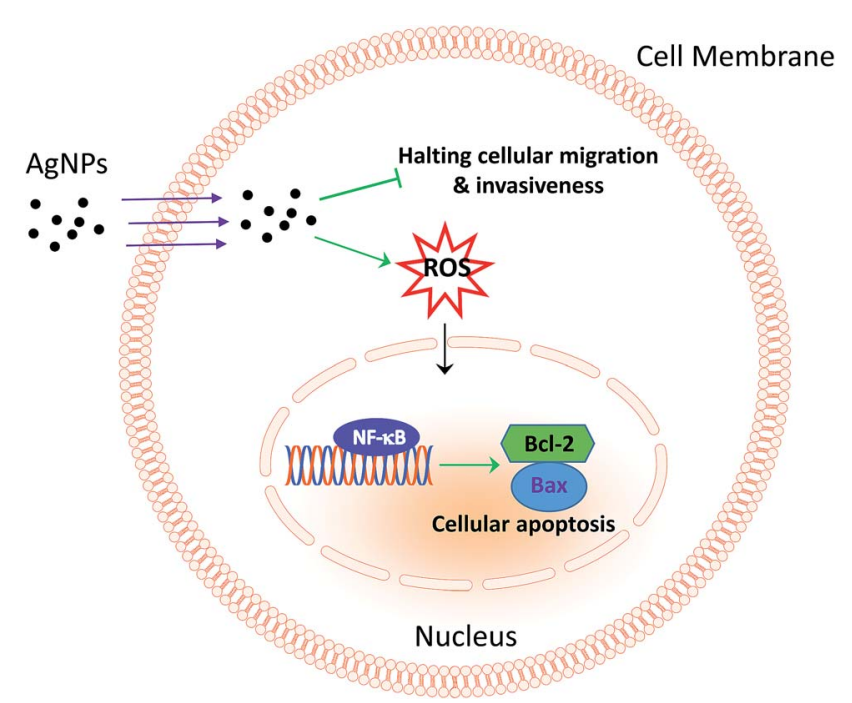

Fig. 6 Scheme summarizing the anticancer effects of AgNPs through the inhibition of migration and invasion against A549 cells and the activation of NF- $\mathrm{KB}$-induced apoptosis. 
inhibit the migration and invasiveness of cells, and thus further lead to cell apoptosis (Fig. 6). Additionally, the biological activity of particles increases as the particle size decreases, since the smaller particles haver larger surface area per unit mass and increased potential for biological interaction. ${ }^{34}$

\section{Conclusions}

In conclusion, this study suggests that size of AgNPs plays a significant role in suppressing the migration and invasion of lung adenocarcinoma cells in vitro, and this inhibitive effect is most pronounced treated with $13 \mathrm{~nm}$ AgNPs, while the effect starts decreasing with the size of $45 \mathrm{~nm}$ and completely vanishes for $92 \mathrm{~nm}$ AgNPs. Further experiment is performed to investigate the possible molecular mechanism, and the results reveal that $13 \mathrm{~nm}$ AgNPs are able to induce the generation of ROS and cell apoptosis by activating NF- $\mathrm{B}$, accompanied with an increase in the expression of NF- $\kappa \mathrm{B}$ target proteins that are pro-apoptotic: Bad, Bax, and the decrease of anti-apoptotic protein: Bcl-2, suggesting that $13 \mathrm{~nm}$ AgNPs may be a potential therapeutic target for lung adenocarcinoma therapy. Although future studies are necessary on proving the anticancer efficacy of AgNPs using in vivo models, the data in this work provides strong indication that AgNPs can be effective preventive agents against lung adenocarcinoma.

\section{Conflicts of interest}

There are no conflicts to declare.

\section{Acknowledgements}

This work was funded by National Natural Science Foundation of China (No. 81700237, 31571172 and 81870343); Fundamental Research Funds for the Central Universities (No. 2018CDYXYX0027 and 2018CDQYYX0042), and Chongqing Research Program of Basic Research and Frontier Technology grant (No. cstc2016jcyjA0407).

\section{Notes and references}

1 F. Islami, L. A. Torre and A. Jemal, Transl. Lung Cancer Res., 2015, 4, 327-338.

2 K. D. Miller, R. L. Siegel, C. C. Lin, A. B. Mariotto, J. L. Krame, J. H. Rowland, K. D. Stein, R. Alteri and A. Jemal, Ca-Cancer J. Clin., 2016, 66, 271-289.

3 N. Katakami, H. Tada, T. Mitsudomi, S. Kudoh, H. Senba, K. Matsui, H. Saka, T. Kurata, Y. Nishimura and M. Fukuoka, Cancer, 2012, 118, 6126-6135.

4 E. V. Cutsem, D. Lambrechts, H. Prenen, R. K. Jain and P. Carmeliet, J. Clin. Oncol., 2011, 29, 1-4.

5 J. K. Horton and S. H. Wilson, Mol. Cancer Res., 2013, 11, 1318.

6 J. K. Horton, J. F. Gleason, H. D. Klepin, S. Isom, D. B. Fried and A. M. Geiger, Cancer, 2011, 117, 4033-4040.

7 M.-L. M. Coussa-Koniski, P. A. Maalouf, N. E. Raad and N. A. Bejjani, Respir. Med. Case. Rep., 2015, 15, 77-79.
8 K. Shedden, J. M. G. Taylor, S. A. Enkemann, M. S. Tsao, T. J. Yeatman, W. L. Gerald, S. Eschrich, I. Jurisica, S. E. Venkatraman, M. Meyerson, R. Kuick, K. K. Dobbin, T. Lively, J. W. Jacobson, D. G. Beer, T. J. Giordano, D. E. Misek, A. C. Chang, C. Q. Zhu, D. Strumpf, S. Hanash, F. A. Shepherd, K. Ding, L. Seymour, K. Naoki, N. Pennell, B. Weir, R. Verhaak, C. Ladd-Acosta, T. Golub, M. Gruidl, J. Szoke, M. Zakowski, V. Rusch, M. Kris, A. Viale, N. Motoi, W. Travis and A. Sharma, Nat. Med., 2008, 14, 822-827.

9 R. R. Arvizo, S. Bhattacharyya, R. A. Kudgus, K. Giri, R. Bhattacharya and P. Mukherjee, Chem. Soc. Rev., 2012, 41, 2943-2970.

10 X. J. Lin, X. Q. Fan, S. J. Xiao, Y. He, W. J. Qi, P. P. Hu, Q. Y. Tan, X. Y. Tong and C. Z. Huang, New J. Chem., 2018, 42, 15311-15314.

11 R. S. Riley, C. H. June, R. Langer and M. J. Mitchell, Nat. Rev. Drug Discovery, 2019, 18, 175-196.

12 A. Gupta, L. Holoidovsky, C. Thamaraiselvan, A. K. Thakur, S. P. Singh, M. M. Meijler and C. J. Arnusch, Chem. Commun., 2019, 55, 6890-6893.

13 F. A. Shiekh, Int. J. Nanomed., 2013, 8, 201-202.

14 S. Kokura, O. Handa, T. Takagi, T. Ishikawa, Y. Naito and T. Yoshikawa, Nanomedicine, 2010, 6, 570-574.

15 X. Zhao, L. Zhou, M. S. R. Rajoka, L. Yan, C. Jiang, D. Shao, J. Zhu, J. Shi, Q. Huang, H. Yang and M. Jin, Crit. Rev. Biotechnol., 2018, 38, 817-835.

16 Y. He, Z. Du, S. Ma, Y. Liu, D. Li, H. Huang, S. Jiang, S. Cheng, W. Wu, K. Zhang and X. Zheng, Int. J. Nanomed., 2016, 11, 1879.

17 A. Dziedzic, R. Kubina, R. J. Bułdak, M. Skonieczna and K. Cholewa, Molecules, 2016, 21, 365.

18 K. Chaloupka, Y. Malam and A. M. Seifalian, Trends Biotechnol., 2010, 28, 580-588.

19 Y. Wang, S. J. Zhen, Y. Zhang, Y. F. Li and C. Z. Huang, J. Phys. Chem. C, 2011, 115, 12815-12821.

20 J. Ling, Y. F. Li and C. Z. Huang, Anal. Chem., 2009, 81, 17071714.

21 D. Steinigeweg and S. Schlücker, Chem. Commun., 2012, 48, 8682-8684.

22 G. Oberdörster, A. Maynard, K. Donaldson, V. Castranova, J. Fitzpatrick, K. Ausman, J. Carter, B. Karn, W. Kreyling, D. Lai, S. Olin, N. Monteiro-Riviere, D. Warheit and H. Yang, Part. Fibre Toxicol., 2005, $2,8$.

23 P. S. Steeg, Nat. Med., 2006, 12, 895-904.

24 L. A. Mina and G. W. Sledge, Nat. Rev. Clin. Oncol., 2011, 8, 323-332.

25 Z. Aktary, M. Alaee and M. Pasdar, Oncotarget, 2017, 8, 32270-32291.

26 H. Yang, R. M. Villani, H. Wang, M. J. Simpson, M. S. Roberts, M. Tang and X. Liang, J. Exp. Clin. Cancer Res., 2018, 37, 266.

27 L. Q. Chen, S. J. Xiao, L. Peng, T. Wu, J. Ling, Y. F. Li and C. Z. Huang, J. Phys. Chem. B, 2010, 114, 3655-3659.

28 L. Q. Chen, S. J. Xiao, P. P. Hu, L. Peng, J. Ma, L. F. Luo, Y. F. Li and C. Z. Huang, Anal. Chem., 2012, 84, 3099-3110. 
29 B. Zhu, Y. Li, Z. Lin, M. Zhao, T. Xu, C. Wang and N. Deng, Nanoscale Res. Lett., 2016, 11, 198.

30 K. S. Siddiqi, A. Husen and R. A. K. Rao, J. Nanobiotechnol., 2018, 16, 14.

31 X. Huang, Y. Teng, H. Yang and J. Ma, Braz. J. Med. Biol. Res., 2016, 49, e5717.

32 H. Chen, Y. Huang, J. Huang, L. Lin and G. Wei, Oncol. Rep., 2017, 37, 865-870.
33 J. Jiang, G. Geng, X. Yu, H. Liu, J. Gao, H. An, C. Cai, N. Li, D. Shen, X. Wu, L. Zheng, Y. Mi and S. Yang, Oncotarget, 2016, 7, 87271-87283.

34 F. R. Cassee, H. Muijser, E. Duistermaat, J. J. Freijer, K. B. Geerse, J. C. Marijnissen and J. H. Arts, Arch. Toxicol., 2002, 76, 277-286. 